Vol 11, Issue 10, 2018

\title{
EFFECTS OF CHROMIUM PICOLINATE ON OXIDATIVE STRESS AND HYPERGLYCEMIA IN EXPERIMENTAL TYPE 2 DIABETIC RATS
}

\author{
HAMITT USLU ${ }^{1}$, GÖZDE ATILA USLU ${ }^{2}$ \\ ${ }^{1}$ Department of Health Care Services, Atatürk Vocational School of Health Services, University of Kafkas, Kars, Turkey. ${ }^{2}$ Department of \\ Physiology, Faculty of Veterinary Medicine, University of Kafkas, Kars, Turkey. E-mail: hamit_uslu@hotmail.com
}

Received: 19 July 2018, Revised and Accepted: 04 Sep 2018

\section{ABSTRACT}

Objective: In this study, we aimed to determine the effects of chromium picolinate (CrPic) on diabetes, one of the most common and fatal diseases in the world, and its associated oxidative damages.

Methods: CrPic (100 $\mu \mathrm{g} / \mathrm{kg})$ and metformin $(1000 \mathrm{mg} / \mathrm{kg})$ were orally administered for 21 days in rats with nicotinamide + streptozotocin-induced Type 2 diabetes.

Results: Significant decreases in fasting blood glucose levels were observed 14 days after initial administration in both CrPic (p<0.01) and metformin $(\mathrm{p}<0.001)$ groups compared with a diabetic control group (DC). Malondialdehyde (MDA) levels of all tissues were significantly higher in the DC group than in a normoglycemic control group $(\mathrm{p}<0.001)$. MDA levels of the CrPic group significantly decreased in heart $(\mathrm{p}<0.05)$ and liver $(\mathrm{p}<0.01)$ tissues. Glutathione (GSH) and catalase (CAT) levels in heart, kidney, and liver tissues increased in CrPic group (GSH p $<0.001, p<0.05$, and $p<0.01$; CAT $p<0.001, p<0.001$, and $p<0.05$, respectively). Superoxide dismutase enzyme levels significantly increased in CrPic group in the liver tissue (p $>0.001$ ), but no such changes were observed in heart and kidney tissues $(\mathrm{p}>0.05)$.

Conclusion: The results obtained from this study indicate that CrPic may be effective in alleviating hyperglycemia and its consequent oxidative damage in experimental Type 2 diabetes.

Keywords: Type 2 diabetes, Hyperglycemia, Oxidative stress, Chromium picolinate.

(C) 2018 The Authors. Published by Innovare Academic Sciences Pvt Ltd. This is an open access article under the CC BY license (http://creativecommons. org/licenses/by/4. 0/) DOI: http://dx.doi.org/10.22159/ajpcr.2018.v11i10.28608

\section{INTRODUCTION}

Diabetes mellitus is a metabolic disease characterized by hyperglycemia resulting from deficiency of insulin secretion, insulin effect, or both $[1,2]$. Chronic hyperglycemia can cause dysfunction and failure of various organs including the eyes, kidneys, nerves, heart, and blood vessels [3-6]. According to the International Diabetes Federation 2018 report, the number of people affected by diabetes today is estimated to be 425 million, while it is estimated to reach 629 million by 2045 [7]. There is no definitive treatment for Type 2 diabetes today. On the other hand, it is stated that the worldwide cost of treating and preventing this disease is US\$ 1 trillion in annually [5]. For this reason, the tendency toward the use of natural antioxidant compounds and essential minerals (such as chromium [Cr], vanadium, selenium, and manganese) for the treatment of diabetes and its complications have increased, and studies have focused on this issue. Many researchers suggest that oxidative stress plays a significant role in the pathogenesis of diabetes mellitus and its complications [8-10]. Levels of reactive oxygen species are tightly controlled by the protective actions of antioxidant enzymes and non-enzymatic antioxidants in healthy individuals [11]. In contrast, antioxidant mechanisms are reduced in diabetic patients, which may, therefore, increase oxidative stress $[12,13]$. $\mathrm{Cr}$ is a trace element that plays a significant role in controlling blood glucose and lipid levels $[14,15]$. It is a ubiquitous metal, occurring in water, soil, and biological systems. The three forms of $\mathrm{Cr}$ occurring in the environment are metallic $\left(\mathrm{Cr}^{0}\right)$, trivalent $\left(\mathrm{Cr}^{3}\right)$, and hexavalent $\left(\mathrm{Cr}^{6}\right) . \mathrm{Cr}^{3}$ is considered to be an essential element, both in animal and human nutrition $[15,16]$. $\mathrm{Cr}$ deficiency is associated with diabetes mellitus, insulin resistance, and glucose sensitivity $[17,18]$. It has also been reported that $\mathrm{Cr}$ deficiency may be seen in patients with Type 2 diabetes [19]. Moreover, it has been indicated that plasma [20] and serum [21,22] Cr levels are lower in diabetic patients than in non-diabetic control (DC) patients.
In this study, we aimed to determine the protective effects of $\mathrm{Cr}^{3}$ against hyperglycemia and hyperglycemia-induced oxidative damage in liver, kidney, and heart tissues.

\section{METHODS}

\section{Experimental design}

This study was conducted under the approval (2016-106) of Kafkas University, Animal Experiments Local Ethics Committee. A total of 40 female Sprague-Dawley rats were divided into four groups of 10 individuals as follows.

\section{Normoglycemic control group (NC)}

This group was fed ad libitum throughout the study. Physiological saline was administered by oral gavage throughout the study to provide the same conditions as those for the experimental groups.

\section{Diabetic control group (DC)}

This group received $110 \mathrm{mg} / \mathrm{kg}$ intraperitoneal (i.p.) nicotinamide (NAD) $+65 \mathrm{mg} / \mathrm{kg}$ intravenous (i.v.) streptozotocin (STZ). In addition, physiological saline was administered by oral gavage, during the study to ensure the same conditions as those for the experimental groups.

\section{Diabetic + chromium picolinate $(D+$ CrPic $)$}

This group was orally administered $110 \mathrm{mg} / \mathrm{kg}$ i.p. NAD $+65 \mathrm{mg} / \mathrm{kg}$ i.v. $\mathrm{STZ}+100 \mu \mathrm{g} / \mathrm{kg}$ orally CrPic.

\section{Diabetic + metformin $(D+M)$}

This group was orally administered $110 \mathrm{mg} / \mathrm{kg}$ i.p. NAD $+65 \mathrm{mg} / \mathrm{kg}$ i.v. $\mathrm{STZ}+1000 \mathrm{mg} / \mathrm{kg}$ orally metformin. 
NAD (Sigma) was administered i.p. 15 min before STZ (Sigma) injection [23]. Rats with fasting blood glucose levels of $\geq 200 \mathrm{mg}$ / dL 7 days after NAD + STZ administration were defined as Type 2 diabetics. The experimental groups were administered $\mathrm{CrPic}$ (GNC) and metformin for 21 days in accordance with the above procedure.

\section{Preparation of study materials}

At the end of the study period, animals were sacrificed by decapitation under $0.4 \mathrm{~mL} / \mathrm{kg}$ pentobarbital sodium anesthesia, and tissue samples (kidney, heart, and liver) were obtained. Tissues were homogenized in phosphate buffer saline (1:9 dilution) using a homogenizer (Wigen Hauser). The homogenates were then centrifuged at 10,000 g for $5 \mathrm{~min}$ at $4^{\circ} \mathrm{C}$ to separate the supernatants.

\section{Biochemical analysis}

Blood glucose levels were periodically determined (days $0,7,14,21$, and 28) using a glucometer after $8 \mathrm{~h}$ of fasting. Malondialdehyde (MDA) and glutathione (GSH) levels were measured using the methods of Placer et al. [24] and Sedlak and Lindsay [25], respectively. The levels of superoxide dismutase (SOD) (Sigma-Aldrich) and catalase (CAT) (Cayman) were determined using spectrophotometric test kits.

Statistical analysis

The SPSS 18 package program was used for statistical analysis of the data. One-way analysis of variance and Tukey's test were used to analyze among group differences. Statistical significance was accepted at $\mathrm{p}<0.05\left(*, \#: \mathrm{p}<0.05, * *, \# \#: \mathrm{p}<0.01\right.$, and $\left.{ }^{* * *}, \# \# \#: \mathrm{p}<0.001\right)$.

\section{RESULTS}

At the beginning of the study, blood glucose levels of the animals ranged from 71 to $98 \mathrm{mg} / \mathrm{dL}$ (mean \pm standard deviation, $\mathrm{n}=40$ ). 7 days after injecting NAD + STZ, blood glucose levels were significantly increased $(p<0.001)$. No significant differences were detected between the DC and experimental groups on days 7 and 14 of the study period ( $p>0.05)$. However, on days 21 and 28 of the study, blood glucose levels significantly decreased as a result of $\mathrm{CrPic}(\mathrm{p}<0.01)$ and metformin $(\mathrm{p}<0.001)$ administration, respectively (Fig. 1).

MDA levels in the heart tissue significantly decreased in the DC group ( $\mathrm{p}<0.001)$. However, MDA level in the heart tissue significantly decreased in the $\mathrm{D}+\mathrm{CrPic}(\mathrm{p}<0.05)$ and $\mathrm{D}+\mathrm{M}(\mathrm{p}<0.001)$ groups. GSH and CAT levels significantly decreased in the DC group $(\mathrm{p}<0.05$ and $\mathrm{p}<0.01$, respectively). As a result of $\mathrm{CrPic}$ and metformin administration, GSH and CAT levels significantly increased $(p<0.001)$. No change was observed in SOD antioxidant enzyme levels ( $p>0.05$ ) (Fig. 2).

MDA levels significantly increased in the kidney tissue of the DC group ( $\mathrm{p}<0.001)$, whereas it decreased in the $\mathrm{D}+\mathrm{M}$ group $(\mathrm{p}<0.01)$. In addition, GSH and CAT levels significantly decreased in the DC group $(\mathrm{p}<0.05$ and $\mathrm{p}<0.001$, respectively) but increased in the $\mathrm{D}+$ CrPic



Fig. 1: Effect of chromium picolinate on fasting blood glucose levels (mean \pm standard deviation, $\mathbf{n}=10$ ). ${ }^{* *} \mathbf{p}<0.01$, ${ }^{* * *} \mathrm{p}<0.001$ as compared with diabetic control group, \#\#\# $\mathbf{p}<0.001$ as compared with normoglycemic control group

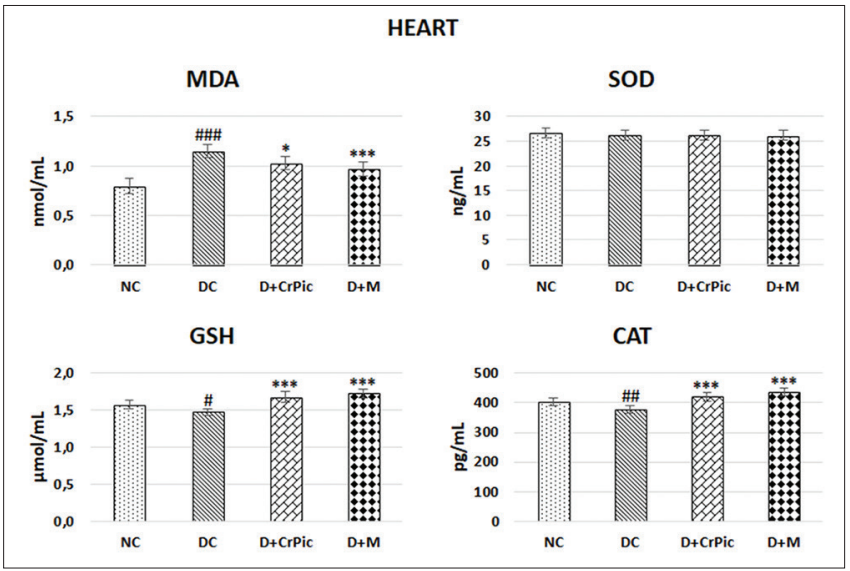

Fig. 2: Effect of chromium picolinate on oxidative stress parameters in heart tissue (mean \pm standard deviation, $\mathrm{n}=10$ )

${ }^{*} \mathbf{p}<0.05, * * * p<0.001$ as compared with diabetic control group, \# $\mathbf{p}<0.05$, \#\# $\mathrm{p}<0.01$, \#\#\# $\mathrm{p}<0.001$ as compared with normoglycemic control group

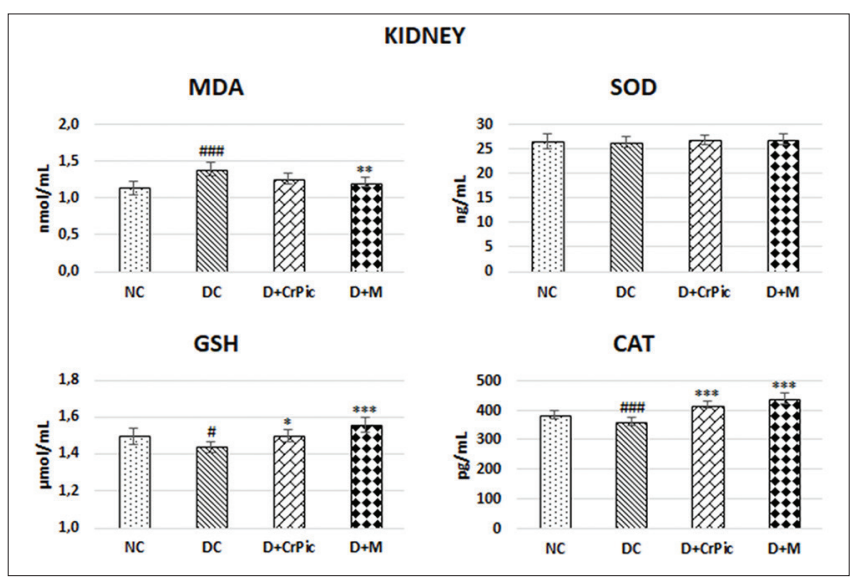

Fig. 3: Effect of chromium picolinate on oxidative stress parameters in kidney tissue (mean \pm standard deviation, $n=10$ ). ${ }^{*} \mathbf{p}<0.05,{ }^{* *} \mathbf{p}<0.01, * * * \mathrm{p}<0.001$ as compared with diabetic control group, \# $\mathrm{p}<0.05$, \#\#\# $\mathrm{p}<0.001$ as compared with normoglycemic control group

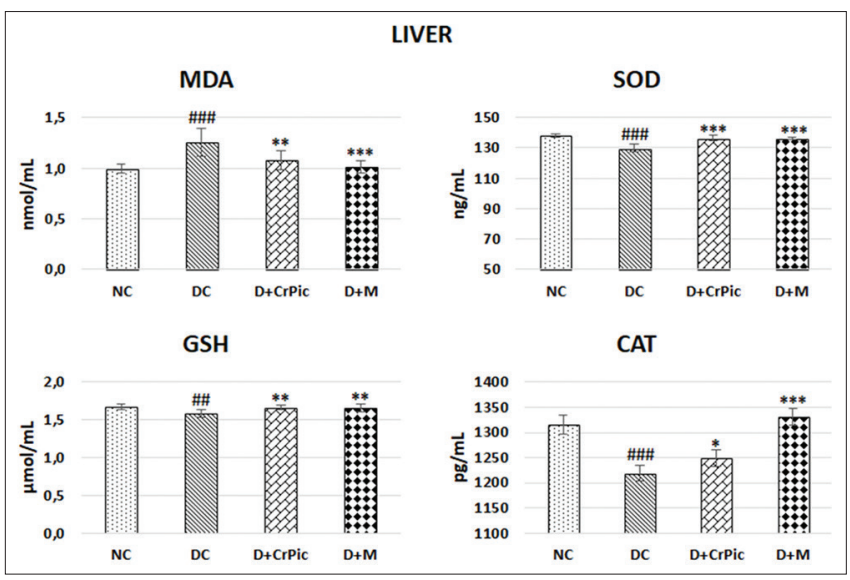

Fig. 4: Effect of chromium picolinate on oxidative stress parameters in liver tissue (mean \pm standard deviation, $\mathrm{n}=10$ ). ${ }^{*} \mathbf{p}<0.05, * * p<0.01, * * * p<0.001$ as compared with diabetic control group, \#\#p<0.05, \#\#\#p<0.001 as compared with normoglycemic control group 
$(\mathrm{p}<0.05$ and $\mathrm{p}<0.001$, respectively) and $\mathrm{D}+\mathrm{M}(\mathrm{p}<0.001)$ groups. No significant differences were detected between SOD levels in the groups ( $p>0.05$ ) (Fig. 3).

MDA levels in the liver tissue of the DC group were found to be significantly higher than in that of the NC group $(\mathrm{p}<0.001)$. MDA levels in liver tissues of the $\mathrm{D}+\mathrm{CrPic}$ and $\mathrm{D}+\mathrm{M}$ groups significantly decreased $(\mathrm{p}<0.01$ and $\mathrm{p}<0.001$, respectively). SOD, GSH, and CAT antioxidant enzyme levels significantly decreased in the DC group $(\mathrm{p}<0.001, \mathrm{p}<0.01$, and $\mathrm{p}<0.001$, respectively) but increased in the $\mathrm{D}+\mathrm{CrPic}(\mathrm{p}<0.001$, $\mathrm{p}<0.01$, and $\mathrm{p}<0.05$, respectively) and $\mathrm{D}+\mathrm{M}(\mathrm{p}<0.001, \mathrm{p}<0.01$, and $\mathrm{p}<0.001$, respectively) groups (Fig. 4).

\section{DISCUSSION}

Insulin resistance is an important cause of diabetes, metabolic syndrome, obesity, hypertension, dyslipidemia, and cardiovascular diseases [26,27]. In Type 2 diabetes, treatment aims to increase insulin sensitivity. This study demonstrated that $\mathrm{CrPic}$ can increase insulin sensitivity and reduce hyperglycemia in diabetic rats (Fig. 1). Many other studies have previously demonstrated that $\mathrm{CrPic}$ can lower blood glucose levels in animals and diabetic patients [11,28-30]. Doddigarla et al. stated that CrPic and melatonin each alone and in combination decreased blood glucose levels in high carbohydrate diet-fed male rats [31]. Refaie et al. also reported that CrPic did not alter blood glucose in non-diabetic rats but significantly reduced in alloxan-induced diabetes. They stated that $\mathrm{CrPic}$ has also linked this mode of action to the glucose tolerance in the host [32]. Another study indicated that CrPic reduced plasma glucose levels and improved unbalanced carbohydrate metabolism in diabetic rats [33]. CrPic exerts its antihyperglycemic and insulin-sensitizing actions through two mechanisms. The first is through increased GLUT4 expression [34] and the second through the regulation of lipid and carbohydrate metabolism [35].

Hyperglycemia can lead to decreased antioxidant enzyme levels despite increases in free radical levels in diabetes mellitus $[11,36]$. Increase in lipid peroxidation and activation of the hexosamine pathway, polyol pathway, and protein kinase $\mathrm{C}$ increase the production of free oxygen radicals $[37,38]$. Nowadays, researchers have stated that antioxidants obtained from natural sources as well as some trace elements such as CrPic can help prevent diabetes and its complications $[14,15]$. Another study stated that $\mathrm{Cr}$ supplementation decreased plasma glucose, TBARS, and HbA1c levels, while it increased levels of TAS in Type 2 diabetes patients [39]. Refaie et al. found that diabetic rats have significant reductions in SOD, GPx, and CAT activities in liver tissues. They stated that this reduction may be related to overproduction of ROS and disrupting the activity of these enzymes. In the same study, researchers were determined that CrPic reduced liver MDA levels, whereas increased SOD, CAT, and GPx levels [32]. In the present study, MDA levels in heart, kidney, and liver tissues significantly increased in the DC group compared with the NC group (Figs. 2-4). There were no differences in SOD antioxidant enzyme levels in heart and kidney tissues between groups (Figs. 2 and 3). However, SOD levels in the liver tissue significantly increased in the D + CrPic group compared with those in the DC group (Fig. 4). Moreover, GSH and CAT enzyme levels in all tissues significantly increased in the D + CrPic group (Figs. 2-4). Previous studies have demonstrated that $\mathrm{CrPic}$ supplementation inhibits the increase in lipid peroxidation seen in diabetic patients [40,41]. Sundaram et al. found that CrPic significantly increased liver GSH, GSH reductase, CAT, and SOD enzyme levels in rats with Type 1 diabetes [37]. Al-Rasheed et al. reported the modulating effect of CrPic in myocardial infarctioninduced oxidative stress [42]. However, the mechanism by which CrPic reduces oxidative stress is not fully understood. We hypothesize that CrPic may reduce oxidative damage by reducing fasting glucose levels.

\section{CONCLUSION}

In this study, CrPic was found to be effective in reducing hyperglycemia in Type 2 diabetes and in suppressing lipid peroxidation by enhancing antioxidant mechanisms.

\section{AUTHORS' CONTRIBUTION}

All authors participated equally in the design, analysis, and writing of the research.

\section{CONFLICTS OF INTEREST}

The authors declare that they have no conflicts of interest.

\section{REFERENCES}

1. American Diabetes Association. Diagnosis and classification of diabetes mellitus. Diabetes Care 2004;27:5-10.

2. Kalsi A, Singh S, Taneja N, Kukal S, Mani S. Current treatments for Type 2 diabetes, their side effects and possible complementary treatments. Int J Pharm Pharm Sci 2015;7:13-8.

3. American Diabetes Association. Diagnosis and classification of diabetes mellitus. Diabetes Care 2012;35:64-1.

4. Paneni F, Beckman JA, Creager A, Cosentino F. Diabetes and vascular disease: Pathophysiology, clinical consequences, and medical therapy: Part I. EHJ 2013;34:2436-43.

5. Shaikh H, Shrivastava VK. Effects of streptozotocin induced diabetes mellitus Type 1 on the rat brain antioxidant status and activity of acetylcholinesterase: A novel and potential treatment by vitex negundo. Int $\mathrm{J}$ Pharm Pharm Sci 2014;6:252-6.

6. Banerjee A, Maji B, Mukherjee S, Chaudhuri K, Seal T. In vitro antidiabetic and anti-oxidant activities of ethanol extract of tinospora sinensis. Int J Curr Pharm Res 2017;9:42-7.

7. International Diabetes Federation: Diabetes Complications Congress, Hyderabad, India 25-27 October 2018. Available from: https://www.idf. org/our-activities/congress/hyderabad-2018.html.

8. Brownlee M. Biochemistry and molecular cell biology of diabetic complications. Nature 2001;414:813.

9. Vinotha AT, Palanimuthu P. Effect of enalapril and metformin on oxidative stress in newly diagnosed Type 2 diabetes mellitus and hypertensive patients. Asian J Pharm Clin Res 2016;9:69-2.

10. Hopps E, Noto D, Caimi G, Averna MR. A novel component of the metabolic syndrome: The oxidative stress. Nutr Metab Cardiovasc Dis 2010;20:72-7.

11. Matough FA, Budin SB, Hamid ZA, Alwahaibi N, Mohamed J. The role of oxidative stress and antioxidants in diabetic complications. Squ Med 2012;12:5-18.

12. Rains JL, Jain SK. Oxidative stress, insülin signaling, and diabetes. Free Radic Biol Med 2011;50:567-5.

13. Maritim AC, Sanders RA, Watkins JB $3^{\text {rd }}$. Diabetes, oxidative stress, and antioxidants: A review. J Biochem Mol Toxicol 2003;17:24-38.

14. Jain SK, Kannan K. Chromium chloride inhibits oxidative stress and TNF-alpha secretion caused by exposure to high glucose in cultured U937 monocytes. Biochem Biophys Res Commun 2001;289:687-1.

15. Cefalu WT, Hu FB. Role of chromium in human health and in diabetes. Diabetes Care 2004;27:2741-51

16. Lewicki S, Zdanowski R, Kryżowska M, Lewicka A, Dębski B, Niemcewicz M, et al. The role of chromium III in the organism and its possible use in diabetes and obesity treatment. Ann Agric Environ Med 2014;21:331-5.

17. Striffler JS, Polansky MM, Anderson RA. Dietary chromium decrease sinsülin resistance in rats fed a high-fat, mineral-imbalanced diet. Metabolism 1998;47:396.

18. Abdourahman A, Edwards JG. Chromium supplementation improves glucose tolerance in diabetic goto-kakizaki rats. IUBMB Life 2008;60:541-8.

19. Nancy AL, Reasner CA. Beneficial effect of chromium supplementation on serum triglyceride levels in NIDDM. Diabetes Care 1994;17:1449-52.

20. Rajendran K, Manikandan S, Nair LD, Karuthodiyil R, Vijayarajan N, Gnanasekar R, et al. Serum chromium levels in Type 2 diabetic patients and its association with glycaemic control. J Clin Diagn Res 2015;9:OC05-8

21. Rajpathak S, Rimm EB, Li T, Morris JS, Stampfer MJ, Willett WC, et al. Lower toenail chromium in men with diabetes and cardiovascular disease compared with healthy men. Diabetes Care 2004;27:2211-6.

22. Hasan HG, Ismael PA, Aziz, NM. Evaluation of serum chromium levels in patients with Type 1 and 2 diabetes mellitus and insülin resistance. Int J Basic Appl Sci 2012;12:69-3.

23. Shirwaikar A, Rajendran K, Kumar CD, Bodla R. Antidiabetic activity of aqueous leaf extract of Annonasquamosa in streptozotocinnicotinamide Type 2 diabetic rats. J Ethnopharmacol 2004;91:171-5

24. Placer ZA, Cushman LL, Johnson BC. Estimation of product of lipid 
peroxidation (malonyldialdehyde) in biochemical systems. Anal Biochem 1966;16:359-4

25. Sedlak J, Lindsay RH. Estimation of total, protein-bound, and nonprotein sulfhydryl groups in tissue with ellman's reagent. Anal Biochem 1968;25:192-5.

26. Kohli P, Greenland P. Role of the metabolic syndrome in risk assessment for coronary heart disease. JAMA 2006;295:819-21.

27. Cortez-Dias N, Martins S, Fiuza M. Metabolic syndrome: An evolving concept. Rev Port Cardiol 2007;26:1409-21.

28. Anderson RA, Cheng N, Bryden NA, Polansky MM, Cheng N, Chi J, et al. Elevated intakes of supplemental chromiumim prove glucose and insülin variables in individuals with Type 2 diabetes. Diabetes 1997;46:1786-91.

29. Preuss HG, Montamarry S, Echard B, Scheckenbach R, Bagchi D. Long-term effects of chromium, grape seed extract, and zinc on various metabolic parameters of rats. Mol Cell Biochem 2001;223:95-2.

30. Stearns DM. Is chromium a traceessential metal? Biofactors 2000;11:149-62.

31. Doddigarla Z, Ahmad J, Parwez I. Effect of chromium picolinate and melatonin either in single or in a combination in high carbohydrate dietfed male wistar rats. Biofactors 2016;42:106-14.

32. Refaie FM, Esmat AY, Mohamed AF, Nour WH. Effect of chromium supplementation on the diabetes induced-oxidative stress in liver and brain of adult rats. Biometals 2009;22:1075.

33. Sundaram B, Singhal K, Sandhir R. Ameliorating effect of chromium administration on hepatic glucose metabolism in streptozotocininduced experimental diabetes. Biofactors 2012;38:59-8.

34. Chen G, Liu P, Pattar GR, Tackett L, Bhonagiri P, Strawbridge AB, et al. Chromium activates glucose transporter 4 trafficking and enhances insulin-stimulated glucose transport in 3T3-L1 adipocytes via a cholesterol-dependent mechanism. Mol Endocrinol 2006;20:857-70.

35. Sundaram B, Singhal K, Sandhir R. Anti-atherogenic effect of chromium picolinate in streptozotocin-induced experimental diabetes. J Diabetes 2013;5:43.

36. Nagarajrao R, Alharbi SA. Relationshıp between oxidant and antioxidant enzymes status in type 2 diabetic patients with nephropathy in saudi population. Asian J Pharm Clin Res 2018;11:363-8.

37. Sundaram B, Aggarwal A, Sandhir R. Chromium picolinate attenuates hyperglycemia induced oxidative stress in streptozotocin-induced diabetic rats. J Trace Elem Med Bio 2013;27:117-1.

38. Kuyvenhoven JP, Meinders AE. Oxidative stress and diabetes mellitus: Pathogenesis of long-term complications. Eur J Intern Med 1999;10:9-19.

39. Lai MH. Antioxidant effects and insulin resistance improvement of chromium combined with Vitamin C and E supplementation for Type 2 diabetes mellitus. J Clin Biochem Nutr 2008;43:191-8.

40. Jain SK, Patel P, Rogier K, Jain SK. Trivalent Chromium inhibits protein glycosylation and lipid peroxidation in high glucose-treated erythrocytes. Antioxid Redox Signal 2006;8:238-1.

41. Jain SK, Rains JL, Croad JL. Effect of chromium niacinate and chromium picolinate supplementation on lipid peroxidation, TNFalpha, IL-6, CRP, glycated hemoglobin, triglycerides, and cholesterol levels in blood of streptozotocin-treated diabetic rats. Free Radic Biol Med 2007;43:1124-31.

42. Al-Rasheed NM, Attia, HA, Mohamed, RA, Al-Rasheed NM, AlAmin MA. Preventive effects of selenium yeast, chromium picolinate, zinc sulfate and their combination on oxidative stress, inflammation, impaired angiogenesis and atherogenesis in myocardial infarction in rats. J Pharm Pharm Sci 2013;16:848-67. 